\section{Canadian Association of Gastroenterology Research Committee report}

\author{
Stephen Vanner MD \\ Chair, CAG Research Committee \\ Queen's University, Kingston, Ontario
}

$\mathrm{T}$

The goal of the Research Committee is to build, in collaboration with the Canadian Institutes of Health Research (CIHR) and the Canadian Association of Gastroenterology (CAG) partners, Canadian capacity and expertise in the discipline of gastroenterology and nutrition, and to promote excellence in research. As chair, I am pleased to update the CAG membership and The Canadian Journal of Gastroenterology readership on the activities of the Research Committee over the past months.

I gratefully acknowledge the work completed by the entire Research Committee (Table 1). On behalf of the CAG, I would like to thank Dr Chris Chadee (Chair 2005-2008) and committee members Drs Jan Huizinga, Karen Madsen, DonnaMarie McCafferty and Paul Moayyedi who completed their term this past February. The assistance of CAG National Office staff - Mr Paul Sinclair, the CAG National Executive Director, Ms Sandra Daniels, Manager and Ms Palma Colacino, Administrative Assistant - is also appreciated.

Details relating to eligibility and application processes for all of the following awards are available on the CAG Web site at $<$ www.cag-acg.org/research.aspx $>$. The review and assessment of every application complies with CIHR standards and guidelines and any potential conflicts of interest are meticulously identified and avoided.

\section{Grants}

Six applications in the New Investigator competition and eight applications in the Operating Grant categories were reviewed. One New Investigator Grant and five Operating Grants were awarded (Table 2).

\section{Fellow-to-Faculty Transition Award}

Three applications for transition awards were received in this year's competition. One award, generously partnered with the Crohn's and Colitis Foundation of Canada (CCFC) and CIHR, was awarded (Table 3).

\section{CAG-CIHR-partnered Postdoctoral Operating Fellowship}

Program

The fellowship program is the cornerstone in the CAG research activities and its sustained success makes it a model for

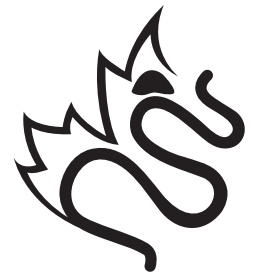

Canadian Association of Gastroenterology

Francais en page 1002

\begin{tabular}{llc}
\multicolumn{3}{l}{ TABLE 1 } \\
Members of the Canadian Association of Gastroenterology \\
\multicolumn{2}{l}{ Research Committee (2008-2009) } & \\
\hline Member & Institution & Term \\
\hline Chair - Stephen Vanner (MD) & Queen's University & $2008-2011$ \\
Mark Silverberg (MD, PhD) & University of Toronto & $2006-2009$ \\
John Brumell (PhD) & University of Toronto & $2006-2009$ \\
Francois Boudreau (PhD) & University of Sherbrooke & $2007-2010$ \\
Thomas Michalak (MD) & Memorial University & $2007-2010$ \\
Bruce Vallance (PhD) & University of British Columbia & $2007-2010$ \\
Paul Beck (MD) & University of Calgary & $2008-2011$ \\
Alan Lomax (PhD) & Queen's University & $2008-2011$ \\
John Marshall (MD) & McMaster University & $2008-2011$ \\
Dana Philpott (PhD) & University of Toronto & $2008-2011$ \\
Elena Verdu (PhD) & McMaster University & $2008-2011$ \\
Isabella Tai (MD) & University of British Columbia & $2008-2011$ \\
\hline
\end{tabular}

other societies. This year, 33 fellowship applications were received. With support from CIHR, the CCFC, and CAG's industrial partners (see acknowledgements), 15 fellowships were funded (Table 4) - a 45\% success rate. Twelve of 24 applications (50\%) from $\mathrm{PhD}$ scientists and three of nine (33\%) applications from MD scientists were funded.

\section{CAG summer studentships}

It is critical that young investigators be supported at all levels of their training. Thus, in partnership with the CCFC, 20 students received awards (salary plus a small operating budget; $\$ 6,000 /$ award) to work in laboratories of recent or established investigators whose interests cover many facets of gut function (Table 5). Twenty-six applications were reviewed giving an approximate success rate of $77 \%$ in this year's competition.

\section{Resident Research Program}

Six applications were reviewed for this competition. One award was made available with the generous partnership from Procter \& Gamble (Table 6).

The CAG is proud to acknowledge its Benefactor Corporate Sponsors:
Abbott Canada
AstraZeneca Canada Inc
Axcan Pharma Inc
Olympus Canada Inc

Pentax Canada Inc Procter \& Gamble Pharmaceuticals Schering-Plough Canada Inc

UCB Pharma Inc 
TABLE 2

Canadian Association of Gastroenterology-Canadian Institutes of Health Research partner-funded grants (2008)

\begin{tabular}{lllll}
\hline Candidate & Industrial partner & Years & Institution & Type of grant \\
\hline Michael Beyak & Nycomed Canada & 2 & Queen's University & New Investigator \\
Alan Barkun & Olympus Canada & 2 & McGill University & Operating \\
Christophe Faure & Abbott Canada & 2 & University of Montreal & Operating \\
Gilaad Kaplan & Abbott Canada & 2 & University of Calgary & Operating \\
Monika Keelan & AstraZeneca Canada Inc & 2 & University of Alberta & Operating \\
Elyanne Ratcliffe & AstraZeneca Canada Inc & 1 & McMaster University & Operating \\
\hline
\end{tabular}

${ }^{*}$ No applications were received for the Shire IBD Operating Grant

TABLE 3

Canadian Association of Gastroenterology-Canadian Crohn's and Colitis Foundation of Canada-Canadian Institutes of Health Research partner-funded Transition Award (2008)

\begin{tabular}{lcc}
\hline Candidate & Years & Institution \\
\hline Aleixo Muise & 4 & The Hospital for Sick Children \\
\hline
\end{tabular}

Congratulations to all the successful award recipients. We look forward to your contributions and your continued participation in Canadian GI research and CAG activities. And again, many thanks to CIHR and the CAG partners - the 20 summer studentships, one resident research award, 15 fellowships, one transition award, and six grants add up to a research dollar commitment in 2008 of $\$ 2,455,000$ !

Canadian Digestive Diseases Week 2008 and the 4th Annual Canadian Association for the Study of the Liver winter meeting

In addition to reviewing research applications, the other main role of the research committee is review of abstracts submitted to the Canadian Digestive Diseases Week (CDDW) which showcases the best of Canadian GI research. A total of 306 abstracts were accepted to the core CDDW/Canadian Association for the Study of Liver (CASL) Winter Meeting scientific program; 48 as CAG or CASL oral presentations and the remainder in one of three poster sessions.

The following are the 2008 recipients of CAG awards:

- Dr Stephen Vanner (Queen's University, Kingston, Ontario) Research Excellence Award

- Dr John Marshall (McMaster University, Hamilton, Ontario) Young Investigator Award

- Dr Phil Sherman (The Hospital for Sick Children, Toronto, Ontario) Visiting Professor Award

- Dr Des Leddin (Dalhousie University, Halifax, Nova Scotia) Education Excellence Award

- Dr Sylvain Coderre (University of Calgary, Calgary, Alberta) Young Educator Award

- Dr Stephen Collins (McMaster University, Hamilton, Ontario) The RD McKenna Memorial Lecturer.

This year's student research prizes were awarded, based on the quality of submitted CDDW abstracts to: Ms J Rybicka, University of Calgary and Mr L Kalishuk, University of Calgary (CAG sponsored) and Ms M Hunter, University of Calgary and Mr M Legeune, University of Calgary (CCFC sponsored).

The CDDW Implementation Committee has the program well under way for the 2009 meeting. You can review the preliminary program and register for the meeting on the CAG Web site at <www.cag-acg.org/cddw.aspx $>$.

TABLE 4

Canadian Association of Gastroenterolgy (CAG)-Canadian Institutes of Health Research partner-funded Postdoctoral Fellowships (2008)

\begin{tabular}{llcll}
\hline Candidate & Industrial partner* & Years & Institution & Supervisor(s) \\
\hline Francisco Bautista-Cruz & AstraZeneca Canada Inc & 2 & Queen's University & William Paterson \\
Donna Daly & Axcan Pharma Inc & 2 & Queen's University & Michael Beyak \\
Eduardo Diez & CAG & 1 & McGill University & Samantha Gruenheid \\
Pierre-Yves Gougeon & Janssen-Ortho & 2 & Queen's University & Michael Blennerhassett \\
Smita Halder & Schering Canada & 2 & University of Toronto & Mark Silverberg \\
Christina Hirota & Abbott Canada & 2 & University of Calgary & Wallace MacNaughton \\
Yongzhong Hou & AstraZeneca Canada Inc & $2(+1)$ & University of Calgary & Kris Chadee \\
Ju Huang & CCFC & 2 & The Hospital of Sick Children & John Brumell \\
Seamus Hussey & CCFC & 2 & The Hospital of Sick Children & Nicola Jones \\
Marcela Miranda-Morales & AstraZeneca Canada Inc & 2 & Queen's University & Stephen Vanner \\
Marinieve Montero & CCFC & 2 & University of British Columbia & Bruce Vallance \\
Vikas Srivastava & AstraZeneca Canada Inc & $2(+1)$ & University of Calgary & Kris Chadee \\
Christopher Teshima & Ferring Pharmaceuticals & 1 & University of Alberta & Jon Meddings, Richard Fedorak, \\
Rosica Valcheva & Abbott Canada & 2 & University of Alberta & Levinus Dieleman \\
Guangzhi Zhang & BMS & 2 & University of Alberta & Levinus Dieleman \\
\hline
\end{tabular}

*No applications were received for the Pentax Therapeutic Endoscopy Fellowship; BMS Bristol-Myers Squibb Canada; CCFC Crohn's and Colitis Foundation of Canada 
TABLE 5

Canadian Association of Gastroenterolgy-Canadian Crohn's and Colitis Foundation of Canada-funded

Summer Studentships (2008)

\begin{tabular}{|c|c|c|c|}
\hline Candidate & Sponsor & Institution & Supervisor \\
\hline Maaike deVries & Crohn's and Colitis Foundation of Canada & Queen's University & Alan Lomax \\
\hline Akira Gillingham & Crohn's and Colitis Foundation of Canada & McGill University & Samantha Gruenheid \\
\hline Shirley Ho & Crohn's and Colitis Foundation of Canada & University of British Columbia & Isabella Tai \\
\hline Yida Jiang & Crohn's and Colitis Foundation of Canada & University of Toronto & Stephen Girardin \\
\hline Darryl Karpel & Crohn's and Colitis Foundation of Canada & University of Toronto & Ken Croitoru \\
\hline Michelle Ma & Crohn's and Colitis Foundation of Canada & McMaster University & Kathy McCoy \\
\hline Christopher Ma & Crohn's and Colitis Foundation of Canada & University of Calgary & Gilaad Kaplan \\
\hline Natalie Ronaghan & Crohn's and Colitis Foundation of Canada & University of Calgary & Wallace MacNaughton \\
\hline Megan Sherman & Crohn's and Colitis Foundation of Canada & McGill University & Ernest Seidman \\
\hline Hang Shi & Crohn's and Colitis Foundation of Canada & University of Toronto & Jennifer Gommerman \\
\hline Shivangi Trivedi & Crohn's and Colitis Foundation of Canada & University of Toronto & Patricia Brubaker \\
\hline Linda Yuan & Crohn's and Colitis Foundation of Canada & University of Toronto & Dana Philpott \\
\hline Ausma Ahmed & Canadian Association of Gastroenterology & University of Toronto & Patricia Brubaker \\
\hline Michael Catarino & Canadian Association of Gastroenterology & University of Calgary & Derek McKay \\
\hline Jinglan Han & Canadian Association of Gastroenterology & University of Calgary & Mark Swain \\
\hline Ada Hung & Canadian Association of Gastroenterology & University of Toronto & Jan Irvine \\
\hline Émilie L Couture & Canadian Association of Gastroenterology & University of Sherbrooke & Patrick Laprise \\
\hline Pearl Leung & Canadian Association of Gastroenterology & University of Calgary & Kris Chadee \\
\hline Lesley Meng & Canadian Association of Gastroenterology & University of Western Ontario & Carol Creuzenet \\
\hline Kathryn Wills & Canadian Association of Gastroenterology & University of British Columbia & Timothy Kieffer \\
\hline
\end{tabular}

TABLE 6

Canadian Association of Gastroenterolgy-funded Residents Research Award (2008)

\begin{tabular}{lccc}
\hline Candidate & Sponsor & Institution & Supervisors \\
\hline Ken Parhar & Procter \& Gamble & University of Alberta & $\begin{array}{c}\text { Paul Beck, } \\
\text { Derek McKay }\end{array}$ \\
\hline
\end{tabular}

\section{Research Topics in GI Disease VIII Meeting}

Held in October 2008, at The Holiday Inn, Toronto, Ontario, 42 students and trainees, both basic science and clinical, were invited to give oral presentations and six established or junior faculty served as mentors. This really is a trainee meeting, with the students and fellows chairing the sessions and dominating the discussion periods. Feedback from the trainees was once again overwhelmingly positive - clearly this is a beneficial and much-enjoyed event. Financial support was provided by AstraZeneca Canada Inc, the CCFC and the CIHR Institute of Diabetes, Nutrition and Metablolism and the scientific program was reviewed by Drs G Greenberg (University of Toronto), K Croitoru (McMaster University), S Vanner (Queen's University), and G Tolomiczenko (CCFC), with the CAG National Office coordinating the abstract submission, meeting management and event.

It has once again been an excellent year for Canadian GI research and everyone involved deserves congratulations. Should CAG members have questions relating to the work of the Research Committee or proposals on how to expand or promote our activities, please contact me or any member of the committee.

ACKNOWLEDGEMENTS: Funding for the 2008 year from the following partners is gratefully acknowledged: Canadian Institutes of Health Research, Abbott Canada, AstraZeneca Canada, Axcan Pharma, Bristol Myers Squibb Canada, Crohn's and Colitis Foundation of Canada, Ferring Pharmaceuticals, Janssen-Ortho, Nycomed Canada, Olympus Canada, Pentax Canada, Procter \& Gamble Pharmaceuticals, Schering Canada, Shire Canada and UCB Pharma Canada. 


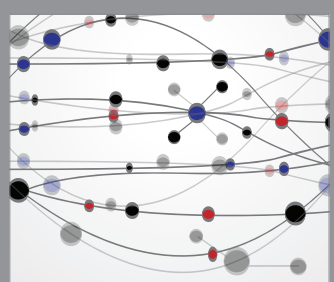

The Scientific World Journal
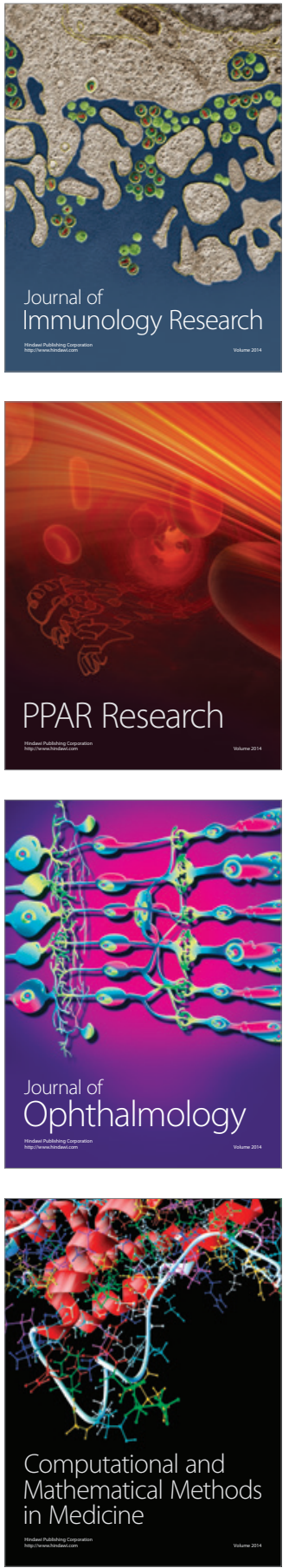

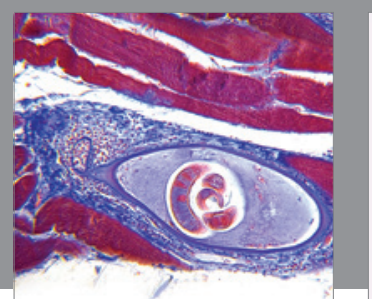

Gastroenterology Research and Practice

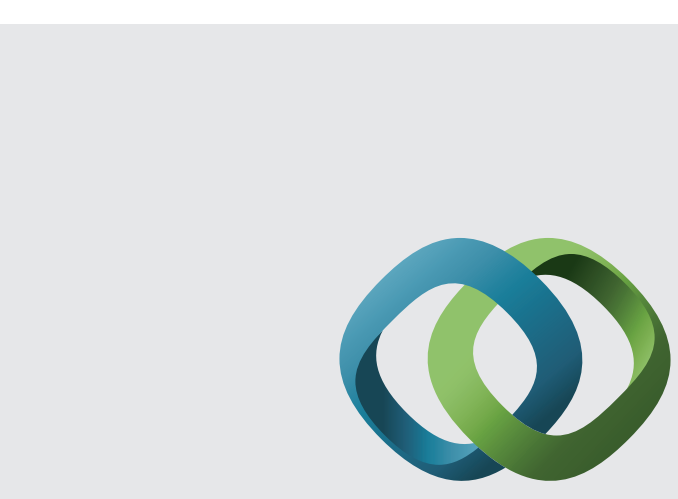

\section{Hindawi}

Submit your manuscripts at

http://www.hindawi.com
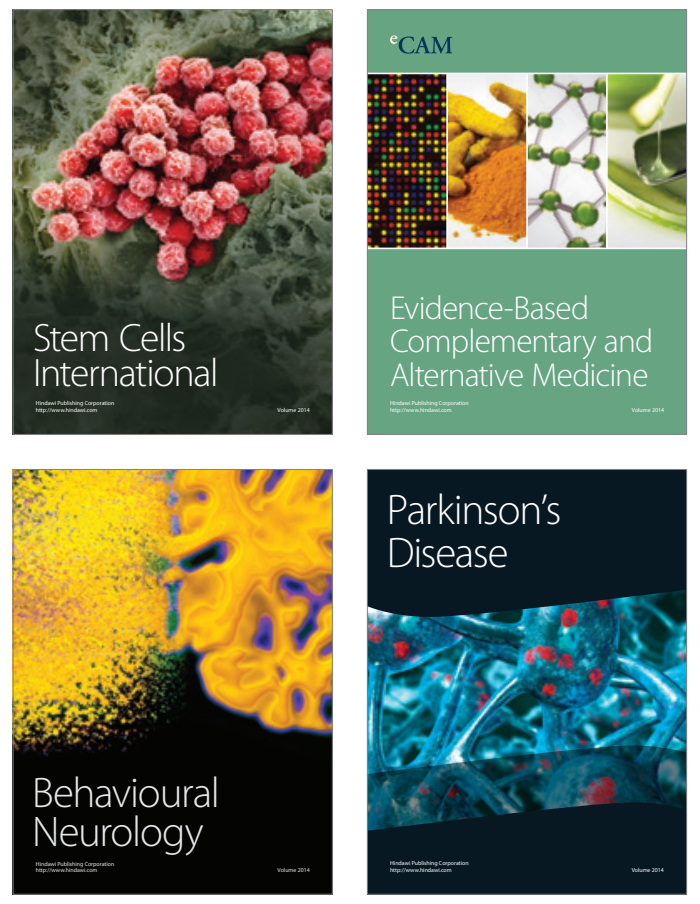
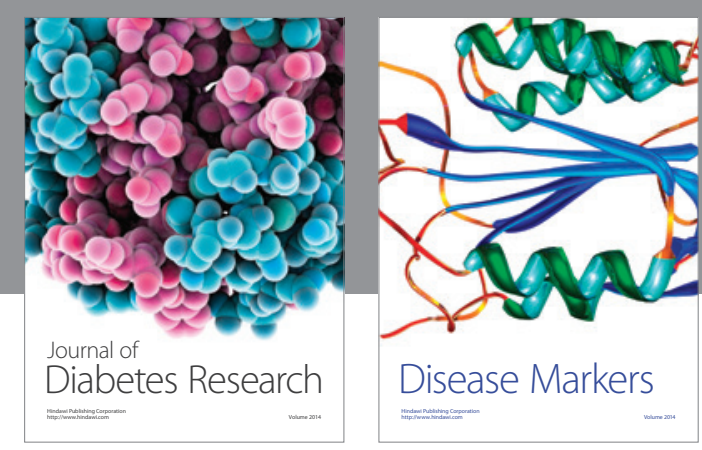

Disease Markers
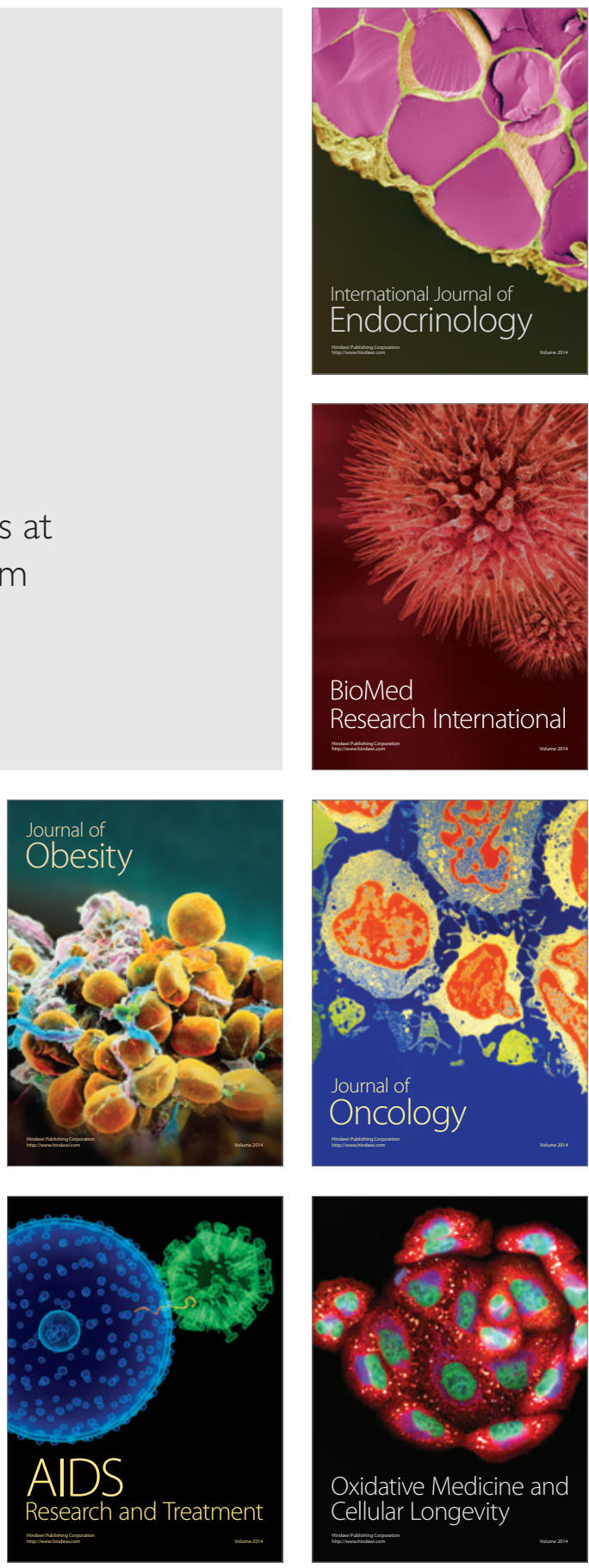